Supplement of Hydrol. Earth Syst. Sci., 23, 4129-4152, 2019

https://doi.org/10.5194/hess-23-4129-2019-supplement

(c) Author(s) 2019. This work is distributed under

the Creative Commons Attribution 4.0 License.

(c) (1)

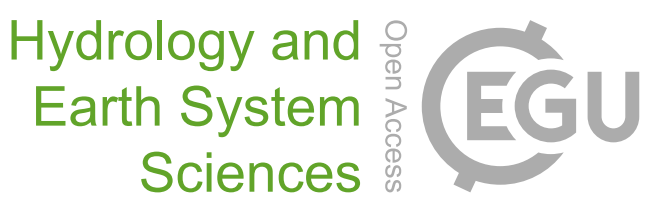

Supplement of

\title{
WHAT-IF: an open-source decision support tool for water infrastructure investment planning within the water-energy-food-climate nexus
}

Raphaël Payet-Burin et al.

Correspondence to: Raphaël Payet-Burin (rapp@env.dtu.dk)

The copyright of individual parts of the supplement might differ from the CC BY 4.0 License. 


\section{WHAT-IF (Water, Hydropower, Agriculture Tool for Investment and Financing): model equations.}

This document is a supplementary material to the publication "WHAT-IF: an open-source decision support tool for water infrastructure investment planning within the Water-Energy-Food-Climate Nexus". The following sections present all equations of the different submodules of WHAT-IF. In the following equations, indices are only detailed when they enhance comprehension and capital letters denote decision variables, while parameters are noted as lower case letters.

\section{Contents}

Water module 2

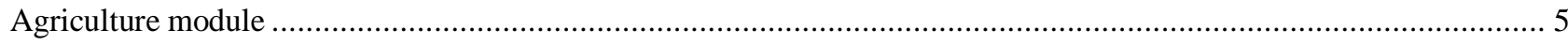

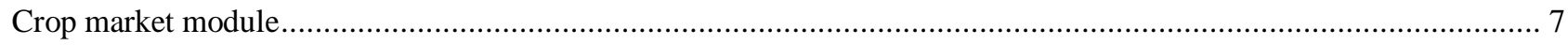

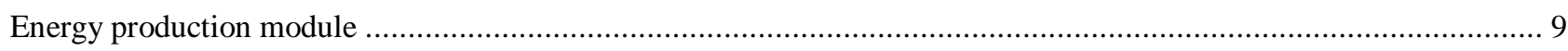

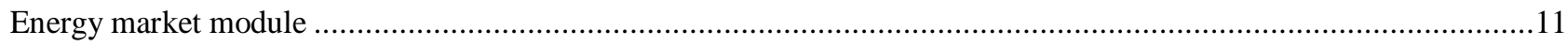

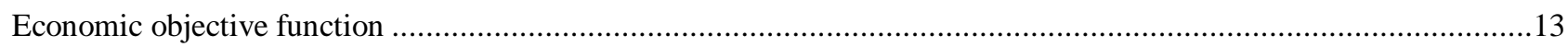

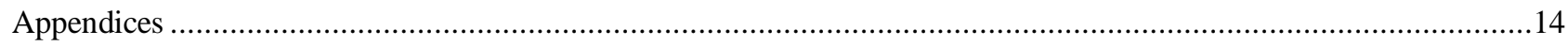

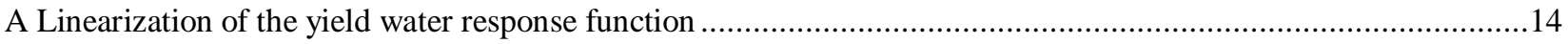

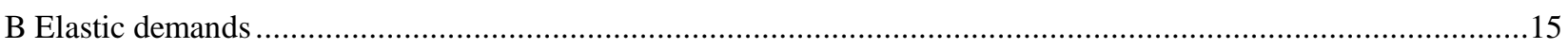

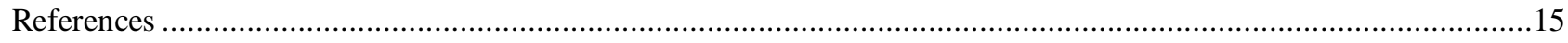




\section{Water module}

Figure 1 shows the conceptual scheme of the water module, while Table 1 lists used indices, parameters and decision variables.:

Water balance, for time step t, catchment c:

$$
\begin{gathered}
q_{\text {runoff }}+Q_{\text {baseflow }}+Q_{\text {in }}=V_{\text {res }}[\mathrm{t}]-V_{\text {res }}[\mathrm{t}-1]+E_{\mathrm{W}}+\sum_{\text {users }} S_{\mathrm{W}} \cdot\left(\frac{1}{1-l_{\text {user }}}-r_{\text {user }}\right)+T_{\mathrm{W}}+Q_{\text {out }} \\
\sum_{\text {users }} S_{\mathrm{W}} \cdot \frac{1}{1-l_{\text {user }}} \leq Q_{\text {in }}+Q_{\text {runoff }}+Q_{\text {baseflow }}
\end{gathered}
$$

Where:

$$
\begin{aligned}
Q_{\text {in }}= & \sum_{\substack{\text { upstream } \\
\text { catchments }}} Q_{\text {out }} \cdot\left(1-l_{\text {river }}\right)+\sum_{\begin{array}{c}
\text { incoming } \\
\text { transfers }
\end{array}} T_{\mathrm{W}} \cdot\left(1-l_{\mathrm{W}, \text { trans }}\right) \\
& E_{\mathrm{W}}=\left(e_{\mathrm{T} 0}-\mathrm{p}\right) \cdot\left(k_{\mathrm{W}} \cdot \frac{V_{\mathrm{W}}[\mathrm{t}]+V_{\mathrm{W}}[\mathrm{t}-1]}{2}+a_{\mathrm{W}}\right) \\
Q_{\text {baseflow }}= & V_{\mathrm{GW}}[\mathrm{t}-1] \cdot\left(1-\mathrm{e}^{-\alpha_{\mathrm{GW}}}\right)+\left(q_{\text {recharge }}-S_{\mathrm{GW}}\right) \cdot\left(1-\frac{1-\mathrm{e}^{-\alpha_{\mathrm{GW}}}}{\alpha_{\mathrm{GW}}}\right)
\end{aligned}
$$

The water balance at the catchment boundaries Eq. (1) equals local runoff, groundwater base flow, and upstream inflows with reservoir storage variation, reservoir evaporation, water supply to catchment users, water transfer, and river outflow. Equation (2) ensures that the releases of the downstream reservoir are not allocated to upstream demand and assumes that return flows are not available for users inside the catchment. The catchment upstream inflow Eq. (3) is defined as the sum of outflows from upstream catchments considering losses in the river, and incoming transfer flows. The evaporative losses in the reservoirs Eq. (4), are based on a linear relation between the reservoir area and volume (parametrized by $\mathrm{k}^{\text {res }}$ and $\mathrm{A}^{\text {res }}$ ), using the average volume in a time period.

Linear reservoirs:

$$
\begin{gathered}
V_{\mathrm{W}}[\mathrm{t}]=V_{\mathrm{W}}[\mathrm{t}-1]+Q_{\mathrm{in}}-E_{\mathrm{W}}-\alpha_{\mathrm{W}} \cdot \frac{V_{\mathrm{W}}[\mathrm{t}]+V_{\mathrm{W}}[\mathrm{t}-1]}{2} \\
V_{\mathrm{GW}}[t]=V_{\mathrm{GW}}[t-1] \cdot \mathrm{e}^{-\alpha_{\mathrm{GW}}}+\left(q_{\text {recharge }}-S_{\mathrm{GW}}\right) \\
\cdot \frac{1-\mathrm{e}^{-\alpha_{\mathrm{GW}}}}{\alpha_{\mathrm{GW}}}
\end{gathered}
$$

Equation (6) only applies to linear reservoirs such as lakes, for which outflow is proportional to the storage volume. It assumes that a separate catchment is defined for the lake. The groundwater volume equation Eq. (7), is the analytical solution of the differential equation $\partial V_{G W} / \partial \mathrm{t}=Q_{\text {recharge }}-S_{\mathrm{GW}}-\alpha_{\mathrm{GW}} \cdot V_{\mathrm{GW}}$ where $Q_{\text {recharge }}$ and $S_{\mathrm{GW}}$ are assumed to be constant during a time step. A similar expression could be used for linear reservoirs in Eq. (6), however, in this case the reservoir evaporation in the water balance would need to be differentiated between controlled and linear reservoirs, therefore we use the discrete solution for all reservoirs.

Capacity constraints:

$$
\begin{gathered}
S_{\mathrm{W}} \leq d_{\mathrm{W}} \\
V_{\mathrm{W}} \leq \bar{V}_{\mathrm{W}} \\
T_{\mathrm{W}} \leq \bar{T}_{\mathrm{W}, \text { trans }}
\end{gathered}
$$

Equations (8), (9) and (10) represent the maximum demand of water users and the capacity limit of the reservoirs and transfer schemes. 
Water supply costs and benefits:

$$
\begin{gathered}
\mathrm{WSC}=\sum_{\mathrm{t}, \mathrm{u}} c_{\mathrm{W}} \cdot S_{\mathrm{W}}[\mathrm{t}, \mathrm{u}]+c_{\mathrm{GW}} \cdot S_{\mathrm{GW}}[\mathrm{t}, \mathrm{u}] \\
\mathrm{WSB}=\sum_{\mathrm{t}, \mathrm{u}} b_{\mathrm{W}} \cdot\left(S_{\mathrm{W}}[\mathrm{t}, \mathrm{u}]+S_{\mathrm{GW}}[\mathrm{t}, \mathrm{u}]\right)
\end{gathered}
$$

Water supply costs in Eq. (11) represent the costs of supplying water to the users (e.g. pumping costs), they differ for surface water and groundwater. The water supply benefits in Eq. (12) represent the value of water allocations for nonagricultural users as the value of water for agriculture is endogenously determined in the agriculture production and crop market modules. The water supply costs and benefits are accounted for in the objective function of the model (Sect. 2.6). Environmental flow requirements:

$$
Q_{\text {out }} \geq q_{\text {env }}
$$

Equation (13) represents the minimum flow at the catchment outlet to preserve the ecosystems or other related activities. As the available runoff may go below the requirement, the constraint can be adapted to available runoff. Some environmental policies are designed to be respected only most of the time (e.g. 4 out of 5 years), such requirements can also be defined in the model.

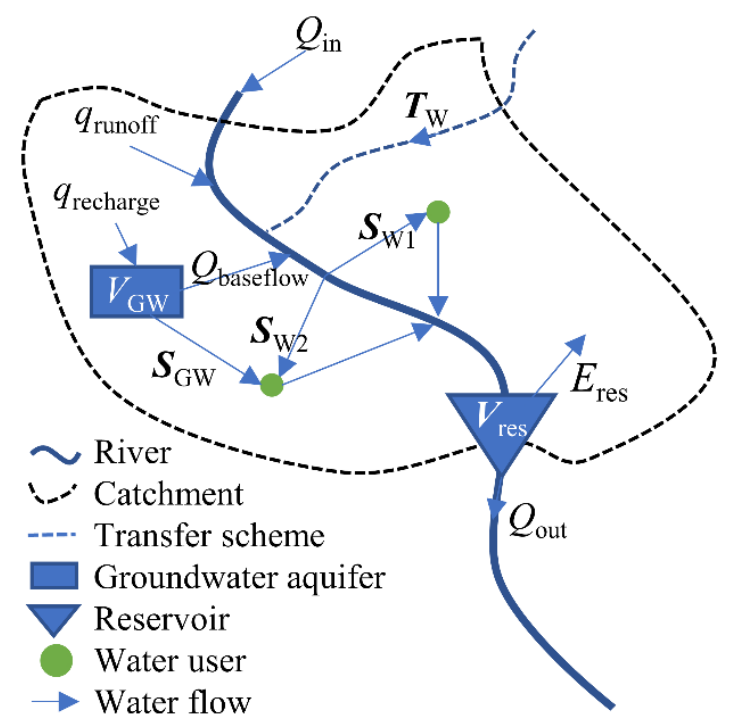

Figure 1: Conceptual scheme of the water management module. The scheme shows the main parameters and decision variables for a catchment with a groundwater aquifer, a reservoir, one incoming transfer scheme and two water users. 
Table 1: Water management indices, parameters and decision variables. Bold characters denote independent decision variables.

\begin{tabular}{|c|c|c|c|}
\hline Notation & Description & $\operatorname{dim}$ & unit \\
\hline \multicolumn{4}{|l|}{ Indices } \\
\hline $\mathrm{t}$ & Time steps & & month \\
\hline c & Catchments & & \\
\hline $\mathrm{aq}$ & Groundwater aquifers & & \\
\hline ts & Transfer schemes & & \\
\hline r & Reservoirs & & \\
\hline $\mathrm{u}$ & Water users & & \\
\hline \multicolumn{4}{|c|}{ Parameters } \\
\hline$q_{\text {runoff }}$ & Runoff & $\mathrm{t}, \mathrm{c}$ & $\mathrm{m}^{3}$ month $^{-1}$ \\
\hline$q_{\text {recharge }}$ & Groundwater recharge & $\mathrm{t}$, aq & $\mathrm{m}^{3}$ month $^{-1}$ \\
\hline$p$ & Precipitation & $t, c$ & $\mathrm{~m}^{3}$ month $^{-1} \mathrm{ha}^{-1}$ \\
\hline$e_{T 0}$ & Reference evapotranspiration & $\mathrm{t}, \mathrm{c}$ & $\mathrm{m}^{3}$ month $^{-1} \mathrm{ha}^{-1}$ \\
\hline$l_{\text {river }}$ & Water losses in the river & c & - \\
\hline $\bar{V}_{W}$ & Reservoir storage capacity & r & $\mathrm{m}^{3}$ \\
\hline$k_{W}$ & Volume-Area linear coefficient & r & ha $\mathrm{m}^{-3}$ \\
\hline$a_{W}$ & Volume-Area linear constant & r & ha \\
\hline$\alpha_{W}$ & Reservoir outflow coefficient & r & month $^{-1}$ \\
\hline$\alpha_{G W}$ & Groundwater outflow coefficient & $\mathrm{aq}$ & month $^{-1}$ \\
\hline$l_{W, \text { trans }}$ & Transfer scheme loss rate & ts & - \\
\hline $\bar{T}_{W, \text { trans }}$ & Capacity of the transfer scheme & ts & $\mathrm{m}^{3}$ month $^{-1}$ \\
\hline$q_{\text {env }}$ & Environmental flow requirement & $\mathrm{t}, \mathrm{c}$ & $\mathrm{m}^{3}$ month $^{-1}$ \\
\hline$d_{W}$ & User net water demand & $\mathrm{t}, \mathrm{u}$ & $\mathrm{m}^{3}$ month $^{-1}$ \\
\hline$l_{\text {user }}$ & User supply loss rate & $\mathrm{u}$ & - \\
\hline$r_{\text {user }}$ & User return flow rate & $\mathrm{u}$ & - \\
\hline$b_{W}$ & Marginal value of water use & $\mathrm{u}$ & $\$ m^{-3}$ \\
\hline$c_{W}$ & Cost of surface water supply & $\mathrm{u}$ & $\$ m^{-3}$ \\
\hline$c_{G W}$ & Cost of groundwater water supply & u & $\$ m^{-3}$ \\
\hline \multicolumn{4}{|c|}{ Decision variables } \\
\hline$Q_{\text {in }, \text { out }}$ & Inlet and Outlet flow, fixed in Eq. (1) & $\mathrm{t}, \mathrm{c}$ & $\mathrm{m}^{3}$ month $^{-1}$ \\
\hline$S_{W}$ & Surface water supply & $\mathrm{t}, \mathrm{u}$ & $\mathrm{m}^{3}$ month $^{-1}$ \\
\hline$S_{G W}$ & Groundwater supply & $\mathrm{t}, \mathrm{u}$ & $\mathrm{m}^{3}$ month $^{-1}$ \\
\hline$V_{\text {res }}$ & Reservoir storage volume & $t, r$ & $\mathrm{~m}^{3}$ \\
\hline$T_{W}$ & Transfer flow & $t, t s$ & $\mathrm{~m}^{3}$ month $^{-1}$ \\
\hline
\end{tabular}




\section{Agriculture module}

Table 2 shows the indices, parameters and decision variables used in the following equations:

Land use, for year y, farming zone fz:

$$
\sum_{\text {cultures }} A \leq \bar{A}
$$

Equation (14) represents the land use constraint per farming zone, cultures on the same area at different period of the year are counted once.

Linearized additive yield water response function, for year y, farming zone fz, culture cul:

$$
P_{\mathrm{C}}=y \cdot \sum_{\mathrm{pt}}\left(A[\mathrm{pt}] \cdot\left(1-\sum_{\mathrm{ps}} k_{\mathrm{Y}}[\mathrm{ps}] \cdot(1-m[\mathrm{pt}, \mathrm{ps}])\right)\right)
$$

The yield water response function (Doorenbos and Kassam, 1979) expresses that crop production is proportional to the maximum yield $(y)$, corrected by the yield response factor $\left(k_{\mathrm{Y}}\right)$, which characterizes how the yield responds to water stress in the different growth phases. This expression is not linear as it is the product of two decision variables (cultivated area and water supply to cultures). The equation is linearized in Eq. (15) by linking the crop water demand satisfaction and the cultivated area in a single decision variable $A[\mathrm{pt}]$ where pt represents the different demand satisfaction paths and $m[\mathrm{pt}, \mathrm{ps}]$ the associated demand satisfaction rates for the different growth phases. Appendix A details the derivation of Eq. (15) and Eq. (16).

Water supply, for year $\mathrm{y}$, farming zone fz, time step t:

$$
S_{\mathrm{W}}[\mathrm{t}, \mathrm{fz}]+S_{\mathrm{GW}}[\mathrm{t}, \mathrm{fz}]=\frac{1}{1-r_{\mathrm{user}}[f z]} \cdot \sum_{\mathrm{cul}, \mathrm{ps}, \mathrm{pt}} a[\mathrm{cul}, \mathrm{ps}, \mathrm{t}] \cdot A[\mathrm{cul}, \mathrm{pt}] \cdot \max \left(0, k_{\mathrm{c}}[\mathrm{cul}, \mathrm{ps}] \cdot e_{\mathrm{T} 0}[\mathrm{t}] \cdot m[\mathrm{pt}, \mathrm{ps}]-p[\mathrm{t}]\right)
$$

The water supply Eq. (16), is the link between the water and agriculture module. The farming zones are considered as water users and their surface and groundwater water supply $\left(S_{\mathrm{W}}+S_{\mathrm{GW}}\right)$ is determined by the cultivated area $(A)$, the water demand by cultures based on FAO $56\left(k_{\mathrm{c}} \cdot e_{\mathrm{T} 0}\right)$, the chosen demand satisfaction path of the cultures $(m)$, and the precipitation $(p)$. The factor $a$ represents the share of the time step falling into a specific growth phase for the different cultures and $r_{\text {user }}$ is the leaching factor of the farming zone to avoid salinization of the soil.

Crop production costs:

$$
\mathrm{CPC}=\sum_{\mathrm{y}, \mathrm{fz}, \mathrm{cul}} c_{\mathrm{cult}} \cdot A
$$

Crop production costs are assumed to be proportional to the cultivated area and are accounted for in the objective function of the model (Sect. 2.6). 
Table 2: Agriculture Production indices, parameters and decision variables

\begin{tabular}{c|l} 
Notation & Description \\
\hline Indices & dim unit \\
$\mathrm{y}$ & Years \\
$\mathrm{fz}$ & Farming zones \\
$\mathrm{ft}$ & Farm types \\
$\mathrm{cr}$ & Crops \\
$\mathrm{cul}$ & Cultures \\
$\mathrm{ps}$ & Growth phases \\
$\mathrm{pt}$ & Demand satisfaction paths \\
\hline
\end{tabular}

\begin{tabular}{c|lll|}
\hline \multicolumn{3}{l}{ Parameters } & \\
$\bar{A}$ & Land capacity & $\mathrm{fz}$ & $\mathrm{ha}$ \\
$y$ & Potential yield & $\mathrm{ft}, \mathrm{cul}$ & $\mathrm{t} \mathrm{ha}^{-1}$ \\
$a$ & Month to phase coefficient & $\mathrm{t}, \mathrm{ps}, \mathrm{cul}$ & - \\
$k_{c}$ & Single crop coefficient & $\mathrm{ps}, \mathrm{cul}$ & - \\
$k_{Y}$ & Yield water response factor & $\mathrm{ps}, \mathrm{cul}$ & - \\
$c_{c u l t}$ & Cultivation costs & $\mathrm{ft}, \mathrm{cul}$ & $\$ \mathrm{ha}^{-1}$ \\
\hline Decision variables & & \\
$A$ & Cultivated area & $\mathrm{y}, \mathrm{fz}, \mathrm{cul}, \mathrm{pt}$ & $\mathrm{ha}^{-1}$ \\
$P_{C}$ & Crop production, fixed in Eq. (15) & $\mathrm{y}, \mathrm{fz}, \mathrm{cul}$ & $\mathrm{t} \mathrm{yr}$
\end{tabular}




\section{Crop market module}

Table 3 shows the indices, parameters and decision variables used in following equations:

Crop balance, for year y, crop market $\mathrm{cm}$, crop cr:

$$
\sum_{\substack{\text { local } \\ \text { farming zones }}} P_{\mathrm{C}}+P_{\mathrm{C}, \text { ext }}+\sum_{\text {imports }} T_{\mathrm{C}} \cdot\left(1-l_{\mathrm{C}, \text { trans }}\right)=S_{\mathrm{C}}+\sum_{\text {exports }} T_{\mathrm{C}}
$$

In Eq. (18) the crop production $\left(P_{\mathrm{C}}\right)$ of local farming zones and external production $\left(P_{\mathrm{C} \text {,ext }}\right)$ (for markets out of the study area) plus crop imports $\left(T_{\mathrm{C}}\right)$ from other markets equals the crop supply to the local market demand $\left(S_{\mathrm{C}}\right)$ plus crop exports $\left(T_{\mathrm{C}}\right)$ towards other markets.

Crop demand and food security constraint, for year y, crop market cm, crop cr:

$$
\begin{gathered}
S_{C} \leq d_{\mathrm{C}} \\
S_{C} \geq d_{\text {min }}
\end{gathered}
$$

In Eq. (19) the crop supply $\left(S_{C}\right)$ is limited to the demand $\left(d_{C}\right)$ of the crop market. Equation (20) represents the minimum supply of crops $\left(d_{\min }\right)$ that must be fulfilled to ensure food security. The demand elasticity for crops is represented by a stepwise function, as described in Appendix B, therefore the demand and value are divided in demand steps (cds). The demand elasticity represents the fact that willingness to pay for crops is decreasing with increasing crop demand.

Crop supply benefits and crop supply costs:

$$
\begin{gathered}
\mathrm{CSB}=\sum_{\mathrm{y}, \mathrm{cm}, \mathrm{cr}, \mathrm{cds}} b_{\mathrm{C}}[\mathrm{cds}] \cdot S_{\mathrm{C}}[\mathrm{cds}] \\
\mathrm{CSC}=\sum_{\mathrm{y}, \mathrm{cm}, \mathrm{cr}} c_{\mathrm{ext}} \cdot P_{\mathrm{C}, \mathrm{ext}}+\sum_{\mathrm{y}, \mathrm{tr}, \mathrm{cr}} c_{\mathrm{C}, \mathrm{trans}} \cdot T_{\mathrm{C}}
\end{gathered}
$$

The crop supply benefits Eq. (21) and costs Eq. (22) are used in the objective function of the model (Sect. 2.6). The benefits represent the value for consumers, the costs are the external production costs and the transaction costs among crop markets. 
Table 3: Crop markets indices, parameters and decision variables

\begin{tabular}{|c|c|c|c|}
\hline Notation & Description & $\operatorname{dim}$ & unit \\
\hline \multicolumn{4}{|l|}{ Indices } \\
\hline $\mathrm{cm}$ & Crop markets & & \\
\hline cds & Crop demand steps & & \\
\hline $\operatorname{tr}$ & Transport routes & & \\
\hline \multicolumn{4}{|c|}{ Parameters } \\
\hline$d_{C}$ & Crop demand & $\mathrm{cm}, \mathrm{cds}$ & $\mathrm{t} \mathrm{yr}^{-1}$ \\
\hline$d_{\min }$ & Crop minimum demand & $\mathrm{cm}$ & ${\mathrm{t} \mathrm{yr}^{-1}}^{-1}$ \\
\hline$l_{C, \text { trans }}$ & Crop transport loss rate & $\mathrm{tr}, \mathrm{cr}$ & - \\
\hline$b_{C}$ & Crop marginal value & $\mathrm{cm}, \mathrm{cr}, \mathrm{cds}$ & $\$ \mathrm{t}^{-1}$ \\
\hline$c_{\text {ext }}$ & External supply costs & $\mathrm{cm}, \mathrm{cr}$ & $\$ \mathrm{t}^{-1}$ \\
\hline$c_{C, \text { trans }}$ & Crop transaction costs & $\mathrm{tr}, \mathrm{cr}$ & $\$ \mathrm{t}^{-1}$ \\
\hline \multicolumn{4}{|c|}{ Decision variables } \\
\hline$S_{C}$ & Crop supply & $\mathrm{y}, \mathrm{cm}, \mathrm{cr}$ & ${\mathrm{t} \mathrm{yr}^{-1}}^{-1}$ \\
\hline$T_{C}$ & Crop transport & $\mathrm{y}, \mathrm{tr}, \mathrm{cr}$ & ${\mathrm{t} \mathrm{yr}^{-1}}^{-1}$ \\
\hline$P_{C, \text { ext }}$ & Crop external production & $\mathrm{y}, \mathrm{cm}, \mathrm{cr}$ & 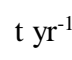 \\
\hline
\end{tabular}




\section{Energy production module}

Table 4 shows the indices, parameters and decision variables in the following equations:

Hydropower discharge and production, for time step t:

$$
\begin{gathered}
\sum_{\text {hydro turbines }} Q_{\text {hydro }} \leq Q_{\text {out }} \\
P_{\text {hydro }}=\gamma \cdot Q_{\text {hydro }}
\end{gathered}
$$

In Eq. (23) the sum of the discharges through the hydropower turbines belonging to the same reservoir is lower or equal to the outflow of the reservoir $Q_{\text {out }}$, the difference being the spill of the reservoir. The same relation applies to run-offthe-river hydropower, except that the hydropower is not linked to a specific reservoir but to a catchment. The power production of hydropower turbines Eq. (24) assumes fixed head of the corresponding reservoir, where $\gamma\left(\mathrm{kWh} \mathrm{m}^{-3}\right)$ is the average water-energy equivalent. The fixed head assumption leads to overestimated discharge capacity and hydropower production during droughts when reservoirs are at low levels. This assumption permits to keep the model linear; it can be relaxed by introducing mixed integer programming or non-linear constraints but comes at the cost of increased computational requirements.

Energy production costs:

$$
\begin{aligned}
& \mathrm{EPC}=\mathrm{OC}+\mathrm{FC}+\mathrm{CC} \\
& \mathrm{OC}=\sum_{\mathrm{t}, \mathrm{s}, \mathrm{hp}} c_{\mathrm{om}, \mathrm{hydro}} \cdot P_{\mathrm{hydro}}+\sum_{\mathrm{t}, \mathrm{ls}, \mathrm{op}} c_{\mathrm{om}, \text { plant }} \cdot P_{\mathrm{plant}}+\sum_{\mathrm{t}, \mathrm{ls}, \mathrm{pt}} c_{\mathrm{om}, \mathrm{tech}} \cdot P_{\text {tech }} \\
& \mathrm{FC}=\sum_{\mathrm{fu}}\left(c_{\text {fuel }}+c_{\mathrm{CO2}} \cdot e_{\mathrm{CO2}}\right) \cdot\left(\sum_{\mathrm{op} \in \mathrm{fu}} P_{\text {plant }} / e_{\mathrm{plant}}+\sum_{\mathrm{pt} \in \mathrm{fu}} P_{\text {tech }} / e_{\text {tech }}\right) \\
& \mathrm{CC}=\sum_{\mathrm{y}} C_{\mathrm{tech}} \cdot\left({ }^{c_{\text {cap }, \text { tech }} / t_{\text {life }}}+c_{\mathrm{fix}, \text { tech }}\right)
\end{aligned}
$$

The energy production costs (EPC) in Eq. (25) are the sum of the marginal operational costs (OC), the fuel consumption and $\mathrm{CO}_{2}$ emission costs $(\mathrm{FC})$ and the capacity expansion costs (CC), they are taken into account in the objective function of the model (Sect. 2.6). 
Table 4: Power production indices, parameters and decision variables

\begin{tabular}{|c|c|c|c|}
\hline Notation & Description & $\operatorname{dim}$ & unit \\
\hline \multicolumn{4}{|l|}{ Indices } \\
\hline hp & Hydropower turbines & & \\
\hline op & Other power plants & & \\
\hline pt & Generic power technologies & & \\
\hline $\mathrm{fu}$ & Fuels & & \\
\hline \multicolumn{4}{|c|}{ Parameters } \\
\hline$\gamma$ & Water-Energy equivalent & hp & $\mathrm{kWh} \mathrm{m}^{-3}$ \\
\hline$e_{\text {hydro }}$ & Efficiency of hydropower plants & hp & - \\
\hline$e_{\text {plant }}$ & Efficiency of other power plants & op & kWh kWh-fuel ${ }^{-1}$ \\
\hline$e_{\text {tech }}$ & Efficiency of power technologies & op & kWh kWh-fuel ${ }^{-1}$ \\
\hline$t_{\text {life }}$ & Lifetime of power technologies & $\mathrm{pm}, \mathrm{pt}$ & $\mathrm{yr}$ \\
\hline$e_{\mathrm{CO} 2}$ & $\mathrm{CO}_{2}$ emission rate of fuels & $\mathrm{fu}$ & $\mathrm{t}-\mathrm{CO}_{2 \mathrm{eq}} \mathrm{kWh}-\mathrm{fuel}^{-1}$ \\
\hline$c_{o m, h y d r o}$ & Operational costs of hydropower turbines & hp & $\$ \mathrm{kWh}^{-1}$ \\
\hline$c_{\text {om,plant }}$ & Operational costs of other power plants & op & $\$ \mathrm{kWh}^{-1}$ \\
\hline$c_{\text {cap,tech }}$ & Capital costs of generic technologies & $\mathrm{pm}, \mathrm{pt}$ & $\$ \mathrm{~kW}^{-1}$ \\
\hline$c_{f i x, t e c h}$ & Fix operational costs of generic technologies & $\mathrm{pm}, \mathrm{pt}$ & $\$ \mathrm{~kW}^{-1} \mathrm{yr}^{-1}$ \\
\hline$c_{\text {om,tech }}$ & Variable operational costs of generic technologies & $\mathrm{pm}, \mathrm{pt}$ & $\$ \mathrm{kWh}^{-1}$ \\
\hline$c_{\text {fuel }}$ & Fuel costs & $\mathrm{pm}, \mathrm{fu}$ & $\$ \mathrm{kWh}$-fuel $^{-1}$ \\
\hline$c_{C 02}$ & $\mathrm{CO}_{2}$ emission costs & - & $\$ \mathrm{t}-\mathrm{CO}_{2 \mathrm{eq}}{ }^{-1}$ \\
\hline \multicolumn{4}{|c|}{ Decision variables } \\
\hline$Q_{\text {hydro }}$ & Discharge through hydropower turbines & $\mathrm{t}, \mathrm{ls}, \mathrm{hp}$ & $\mathrm{m}^{3}$ month $^{-1}$ \\
\hline$P_{\text {hydro }}$ & Hydropower production, fixed in Eq. (24) & $\mathrm{t}, \mathrm{ls}, \mathrm{hp}$ & $\mathrm{kWh}$ month $^{-1}$ \\
\hline$P_{\text {plant }}$ & Other power plant energy production & $\mathrm{t}$, ls, op & $\mathrm{kWh}$ month $^{-1}$ \\
\hline$C_{\text {tech }}$ & Generic technology capacity expansion & $\mathrm{t}, \mathrm{pm}, \mathrm{pt}$ & $\mathrm{kW}$ \\
\hline$P_{\text {tech }}$ & Generic technology production & $\mathrm{t}, \mathrm{ls}, \mathrm{pm}, \mathrm{pt}$ & $\mathrm{kWh}$ month $^{-1}$ \\
\hline
\end{tabular}




\section{Energy market module}

Table 5 shows the indices, parameters and decision variables used in the following equations:

Energy balance, for time step $\mathrm{t}$, load segment ls, power market pm:

$$
\begin{gathered}
\sum_{\mathrm{hp} \in \mathrm{pm}} P_{\mathrm{hydro}}+\sum_{\mathrm{op} \in \mathrm{pm}} P_{\mathrm{plant}}+\sum_{\mathrm{pt}} P_{\mathrm{tech}}+\sum_{\mathrm{t} \mathrm{l} \in \text { imports }} T_{\mathrm{E}} \cdot\left(1-l_{\mathrm{E}, \text { trans }}\right) \\
=S_{\mathrm{E}} \frac{1}{1-l_{\mathrm{E}, \text { supply }}}+\sum_{\mathrm{t} \mathrm{l} \in \text { exports }} T_{\mathrm{E}}
\end{gathered}
$$

Equation (29) is the energy balance at the power markets: the power produced by local hydropower, other power plants and additional capacity plus net imported power through the transmission network, equals the gross power supply to the local demand plus gross exported power.

Power demand, for time step $\mathrm{t}$, load segment ls, power market pm:

$$
S_{E} \leq d_{\mathrm{E}} \cdot d_{\text {load }}
$$

In Eq. (30) the power supplied $\left(\mathrm{S}_{\mathrm{E}}\right)$ is limited to the power demand of the corresponding load segment $\left(D_{E} \cdot d_{\text {load }}\right)$.

Capacities, for time step t, and load segment ls:

$$
\begin{aligned}
P_{\text {hydro }} & \leq \bar{P}_{\text {hydro }} \cdot t_{\text {load }} \\
P_{\text {plant }} & \leq \bar{P}_{\text {plant }} \cdot t_{\text {load }} \cdot e_{\mathrm{CF}} \\
P_{\text {tech }} & \leq C_{\text {tech }} \cdot t_{\text {load }} \cdot e_{\mathrm{CF}} \\
T_{\mathrm{E}} & \leq \bar{T}_{\text {E,trans }} \cdot t_{\text {load }}
\end{aligned}
$$

In Eq. (31), (32) and (33) the hydropower, other power plants and generic technologies power productions (respectively $P_{\text {hydro }}, P_{\text {plant }}$ and $\left.P_{\text {tech }}\right)$ are limited by their capacities $\left(\bar{P}_{\text {hydro }}, \bar{P}_{\text {plant }}\right.$ and $\left.C_{\text {tech }}\right)$ adjusted to the length of the load segment $\left(t_{\text {load }}\right)$ and the eventual load segment capacity factor $\left(e_{\mathrm{CF}}\right)$, constraining some power technologies during the load segment. Similarly, the limited capacity of transmission lines is represented in Eq. (34).

Energy supply benefits and energy transmission costs:

$$
\begin{gathered}
\mathrm{ESB}=\sum_{\mathrm{t}, \mathrm{ls}, \mathrm{pm}} b_{\mathrm{E}} \cdot S_{\mathrm{E}} \\
\mathrm{ETC}=\sum_{\mathrm{t}, \mathrm{ls}, \mathrm{tl}} c_{\mathrm{E}, \mathrm{trans}} \cdot T_{\mathrm{E}}
\end{gathered}
$$

The energy supply benefits (ESB) Eq. (35) and transmission costs (ETC) Eq. (36) are used in the objective function of the model (Sect. 2.6). 
Table 5: Power market parameters and decision variables

\begin{tabular}{|c|c|c|c|}
\hline Notation & Description & $\operatorname{dim}$ & unit \\
\hline \multicolumn{4}{|l|}{ Indices } \\
\hline $\mathrm{pm}$ & \multicolumn{3}{|l|}{ Power markets } \\
\hline ls & \multicolumn{3}{|l|}{ Load segments } \\
\hline \multicolumn{4}{|c|}{ Parameters } \\
\hline$d_{E}$ & Power demand & $\mathrm{t}, \mathrm{pm}$ & $\mathrm{kWh}$ month $^{-1}$ \\
\hline$d_{\text {load }}$ & Share of the demand per load segment & ls & - \\
\hline$t_{\text {load }}$ & Length of load segment & ls & $\mathrm{h}$ month $^{-1}$ \\
\hline$e_{C F}$ & Load segment capacity factor & ls, pt & - \\
\hline $\bar{P}_{\text {hydro }}$ & Capacity of hydropower turbine & hp & $\mathrm{kW}$ \\
\hline $\bar{P}_{\text {plant }}$ & Capacity of other power plants & op & $\mathrm{kW}$ \\
\hline $\bar{T}_{E, \text { trans }}$ & Capacity of the transmission line & $\mathrm{tl}$ & $\mathrm{kW}$ \\
\hline$l_{E, \text { trans }}$ & Power transmission losses & tl & - \\
\hline$l_{E, \text { supply }}$ & Local power supply losses & $\mathrm{pm}$ & - \\
\hline$b_{E}$ & Marginal value of energy & $\mathrm{pm}$ & $\$ \mathrm{kWh}^{-1}$ \\
\hline$c_{E, \text { trans }}$ & Energy transmission costs & tl & $\$ \mathrm{kWh}^{-1}$ \\
\hline \multicolumn{4}{|c|}{ Decision variables } \\
\hline$S_{E}$ & Net Power supply & $\mathrm{t}, \mathrm{ls}, \mathrm{pm}$ & $\mathrm{kWh}_{\text {month }}{ }^{-1}$ \\
\hline$T_{E}$ & Energy transmission & $\mathrm{t}, \mathrm{ls}, \mathrm{tl}$ & $\mathrm{kWh}$ month $^{-1}$ \\
\hline
\end{tabular}




\section{Economic objective function}

The economic module is the objective function of the optimization model. The equations are solved to find the optimal water, agriculture and energy management decision variables minimizing the costs (/maximizing the benefits) resulting from previous modules while respecting the physical, political and economic constraints. In welfare economic terms, this corresponds to the maximization of the total consumer and producer surplus for all commodities represented: water, crops, and energy (see Krugman and Wells (2005) for details on consumer and producer surplus). According to the second welfare economic theorem, any pareto optimal allocation can be reached by a competitive market. This means that the "centrally planned" solution from the economic optimization module, is the same as the individual profit maximization solution, assuming that water, energy and crops could be traded on perfect markets.

The objective function $\varphi$ to maximize is expressed as:

$$
\varphi=\mathrm{WSB}-\mathrm{WSC}+\mathrm{CSB}-\mathrm{CSC}-\mathrm{CPC}+\mathrm{ESB}-\mathrm{ETC}-\mathrm{EPC}
$$

Where WSB represents the water supply benefits Eq. (12), WSC the water supply costs Eq. (11), CSB the crop supply benefits Eq. (21), CSC the crop supply costs Eq. (22), CPC the crop production costs Eq. (17), ESB the energy supply benefits Eq. (35), ETC the energy transmission costs Eq. (36) and EPC the energy production costs which are the sum of the energy operational costs, fuel consumption and $\mathrm{CO}_{2}$ emission costs and the capacity expansion costs Eq. (25). 


\section{Appendices}

\section{A Linearization of the yield water response function}

The water requirement for a specific growth phase (ps) is estimated using the FAO 56 method (Allen et al., 1998), with the reference evapotranspiration $\left(e_{\mathrm{T} 0}\right)$ and a culture and phase specific crop coefficient $\left(k_{\mathrm{c}}\right)$. Therefore, considering the precipitation $(p)$ and the amount of irrigation $\left(\boldsymbol{I}_{\text {rrig }}\right)$ during the growth phase, the crop demand satisfaction rate $\left(\boldsymbol{D}_{\text {rate }}\right)$ can be expressed as follow:

$$
\boldsymbol{D}_{\text {rate }}[\mathrm{ps}]=\min \left(1, \frac{p[\mathrm{ps}]+\boldsymbol{I}_{\mathrm{rrig}}[\mathrm{ps}]}{k_{\mathrm{c}}[\mathrm{ps}] \cdot e_{\mathrm{To}}[\mathrm{ps}]}\right)
$$

The relation between water demand satisfaction of cultures and yield is estimated using the additive yield water response function based on the FAO 33 method (Doorenbos and Kassam, 1979). Crop production $\left(P_{\mathrm{C}}\right)$ is proportional to the product of the cultivated area $(\boldsymbol{A})$ and maximum yield $(y)$, corrected by the yield response factor $\left(k_{\mathrm{Y}}\right)$, which characterizes how the yield responds to water stress in the different growth phases (ps):

$$
P_{\mathrm{C}}=\boldsymbol{A} \cdot y \cdot\left(1-\sum_{\mathrm{ps}} k_{\mathrm{Y}}[\mathrm{ps}] \cdot\left(1-\boldsymbol{D}_{\text {rate }}[\mathrm{ps}]\right)\right)
$$

For irrigated crops, the cultivated area $(\boldsymbol{A})$ and the demand satisfaction rate $\left(\boldsymbol{D}_{\text {rate }}\right)$ are decision variables and therefore, the equation is not linear as it is the product of the two. Considering four growth phases as defined by FAO (initial, development, medium and late), the number of possible combinations between the minimum and optimal demand satisfaction rates through the whole crop growth period is $2^{4}=16$. Consider now $m$ a $16 \times 4$ matrix of all combinations of minimum (0) and optimal (1) demand satisfactions per phase:

$$
\mathrm{m}=\left[\begin{array}{llll}
1 & 1 & 1 & 1 \\
0 & 1 & 1 & 1 \\
& & & \\
0 & 0 & 0 & 0
\end{array}\right]
$$

We can now specify the crop production variable $\boldsymbol{P}_{\mathbf{C}}$ in an equation, linking the crop water demand satisfaction and the cultivated area in a single decision variable $\boldsymbol{A}[\mathrm{pt}]$, using the somewhat artificial notion that the farmer partitions his cultivated area into a selection of the 16 evapotranspiration combinations described by the path index pt. The overall demand satisfaction rate for each growth phase is the weighted average of the selected paths. Then the previous equation can be expressed as:

$$
\boldsymbol{P}_{\mathrm{C}}=y \cdot \sum_{\mathrm{pt}}\left(\boldsymbol{A}[\mathrm{pt}] \cdot\left(1-\sum_{\mathrm{ps}} k_{\mathrm{Y}}[\mathrm{ps}] \cdot(1-m[\mathrm{pt}, \mathrm{ps}])\right)\right)
$$

Which is a linear equation. Finally, for irrigated crops, the amount of irrigation $\left(\boldsymbol{I}_{\text {rrig }}\right)$ during a specific growth phase (ps) can be expressed as:

$$
\boldsymbol{I}_{\text {rrig }}=\sum_{\mathrm{pt}} \boldsymbol{A}[p t] \cdot \max \left(0, k_{\mathrm{c}} \cdot e_{\mathrm{T} 0} \cdot m[\mathrm{pt}, \mathrm{ps}]-p\right)
$$

Where $k_{\mathrm{c}} \cdot e_{\mathrm{T} 0}$ and $p$ are respectively the crop water demand and precipitation during the growth phase. 


\section{B Elastic demands}

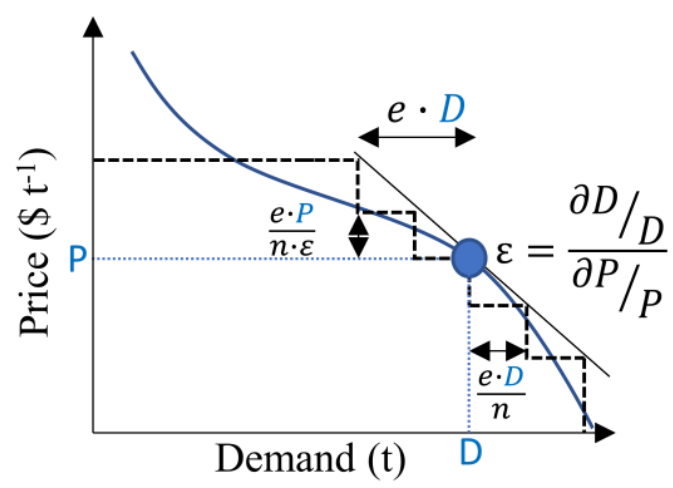

Observed point on demand curve

Real demand curve

-. Stepwise demand curve

Figure B1: Stepwise representation of demand elasticity. $\varepsilon$ represents elasticity, $\mathrm{P}, \mathrm{D}$ are respectively the price and demand of the observed demand point, $\mathrm{e}$ and $\mathrm{n}$ are parameters of the stepwise function, $\mathrm{e}$ is the share of the demand that is elastic, and $\mathrm{n}$ is the number of steps. In the figure $\boldsymbol{\varepsilon}=-\mathbf{1}, \boldsymbol{n}=\mathbf{2}$ and $\boldsymbol{e}=\mathbf{0 . 3}$.

In order to represent the demand curve for crops, a demand point should be defined from observed data (e. g. FAO (2018)). If a demand elasticity is defined, the model will generate a stepwise demand curve representing the elasticity as shown in Figure B1. The stepwise function can be parametrized by setting $e$, the share of the demand that will be elastic and $n S$ the number of steps. Therefore, the Crop demand $\left(D_{C}\right)$ and crop marginal value $\left(v_{C}\right)$ parameters are divided into $1+2$. $n S$ steps as represented on the figure. Increasing the number of steps gives a finer approximation of the demand curve, however it increases the computation time as it increases the number of decision variables.

\section{References}

Allen, R. G., Pereira, L. S., Raes, D. and Smith, M.: Crop evapotranspiration: guidelines for computing crop water requirements. FAO Irrigation and Drainage Paper No. 56, FAO, Rome, Italy., 1998.

Doorenbos, J. and Kassam, A. H.: Yield response to water. FAO Irrigation and Drainage Paper No. 33, Food and Agricultural Organisation of the United Nations, Rome., 1979.

FAO: FAOSTAT, [online] Available from: http://www.fao.org/faostat/en/\#data/QC (Accessed 27 July 2018), 2018. 